\title{
Geospatial Based Coastal Ecotourism Management for Geography Teaching Material Development
}

\author{
Safiah@Yusmah Muhammad Yusoff \\ Deputy Dean (Undergraduate), Faculty of Arts and Social Sciences, \\ University Malaya and Senior Lecturer, Department of Geography, Faculty of Arts and Social Sciences, \\ University Malaya, 50603 Kuala Lumpur, MALAYSIA \\ e_mail:dr.safiah@um.edu.my
}

\begin{abstract}
Geospatial has been widely and extensively used as a research tool across the human activity spectrum. Education sector is no exemption with geospatial being taught in all education institutions, secondary or tertiary. In geography education, tourism courses are among courses that employ geospatial in their teaching and learning material to define the data collection and associate the data with technology which has geographic and locational component. Coastal ecotourism, for example, utilize geospatial in its management where geographic information can be stored in layers and integrated with geographic software program. The information can then be created, stored, manipulated, analyzed and visualized. More interestingly, the result of the spatial information can be integrate with various other research discipline. This paper reviews: 1) geospatial as one of the tools used in geography teaching material; 2) the application of geospatial in coastal ecotourism management; and 3) geospatial based coastal ecotourism management for geography education. A review from geospatial based coastal ecotourism management for geography teaching material development was established. Hence, its effectiveness and efficiency is also discussed.
\end{abstract}

\section{Keywords: Geospatial, Geography, Teaching and Learning, Ecotourism}

\section{Introduction}

The use of communication networks, computers, software, digital data storage and audiovisual systems in our world is referred to as Information and Communication Technology (ICT). There is abundance of benefits especially to students if the ICT are used correctly in the classroom. In Geography, various forms of ICT, especially geospatial technologies, can be used to encourage not only spatial thinking but also making the knowledge acquisition process, more efficient and engaging. The present century learning is focus on opportunities for students to collaborate, share, modify and create knowledge through meaningful pedagogy because it is important to prepare our students for the future. Since many households have internet access, which means our students are already digitally aware, the use of ICT in education not only will benefit and enhance the skills in the workplace in future, but more importantly digital literacy is a skill for life and a core component of learning (Catling, 2005). Therefore, supporting children to be digitally literate is mandatory as the key to effective learning. The range of geography-related ICT expands on those general ICT that are typically used in classrooms, such as word processing software, internet searching, navigating and publishing tools, mind mapping tools, databases, email, simple audio and video software, digital cameras and audio recorders. More specifically geography-related ICT include data visualisation tools and geospatial technologies. Microsoft Excel or Gapminder, infographics, 3D rendering tools such as Google Earth and SketchUp Data visualisation tools are examples of data visualization tools. Geospatial technologies include Global Positioning System (GPS) which uses ground transmitters and satellites orbiting the earth to identify locations on the earth's surface; Geographic Information System (GIS) which can store, edit, 
analyze, and display the geographic data collected through GPS, RS, and other technologies; and remote sensing (aerial and satellite images) which allows aircraft, satellites, ships, and similar vehicles to collect data on large or inaccessible locations. These three main geospatial technology tools provide an incredible boost to research in geography and many other disciplines.

Geospatial is a term used to define the method and technology applied in collecting data which have geographical component or locational information. This means that the records in the dataset have locational information attached to them such as geographic data in the form of coordinates, address, city, or ZIP code (Dempsey, 2014). Examples of geospatial data are Geographic Information System (GIS), Global Positioning System (GPS), satellite imageries and geotagging/georeferencing. Geospatial technology refers to all technology used to acquire, manipulate, and store geographic information. The term geospatial has only entered literature during the late $1980 \mathrm{~s}$ and has been rapidly used since then. Geospatial is always interchangeably used with GIS, although both terms are in fact, different. GIS is defined as a system where geographical data and information are stored in the form of layers and integrated with specific geographical software programs in order for spatial information to be created, stored, manipulated, analyzed and visualized. GIS has been used extensively in site selection, and the biggest difference GIS has compare to previous site selection tools is, it can effectively integrate attribute data of each source, perform spatial analysis, create spatial analysis process, and finally use particular map image to present analysis results (Chang and Lin, 2007).

\section{Geospatial Skills Development in Education}

Geospatial technologies are one of the key ICT that is used as geography teaching material in many universities across the world. They are fantastic tools for disseminating geographic knowledge and encouraging geographic thinking. In ensuring the maximum implementation of geospatial technologies, the spectrum of technologies related to Bloom's taxonomy as shown in Figure 1 is considered. It should be noted that, if used creatively, some of the simpler geospatial technologies can offer opportunities to engage in limited higher-order thinking tasks and activities. Firstly, features exploration and uses of simple geospatial technologies, and how Bloom's Taxonomy can support students' learning. In a geographical inquiry simple geospatial technologies are best suited to examining the 'where' aspects of an issue, identifying patterns and creating simple maps or figures to represent those patterns. A range of resources and support materials is provided. Secondly, data visualisation looks at the use and creation of visual representations of information such as maps, photographs, charts, diagrams and field sketches. The tools for this process can cover a broad range of levels across Bloom's Taxonomy, and infographics (information graphics) and Data Genie are detailed in particular. Thirdly, the exploration on how the tools of interactive technologies can be used to view and add to data, including with more sophisticated data such as interactive and virtual tours. Lastly, how students are able to do more with data and have increased opportunities to engage in higher-order thinking when using intermediate geospatial technologies are illustrated (Catling, 2005).

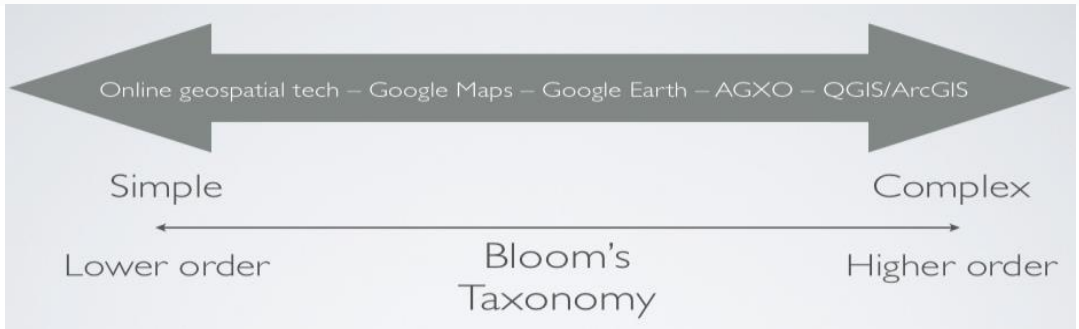

Figure 1. Bloom's Taxonomy and its Connection with Geospatial Technologies (Catling, 2005) 
It has been stressed that spatial thinking plays a vital role in higher education and academic research. Spatial thinking in science progresses through three steps: extracting spatial structures, performing spatial transformations and drawing functional inferences. In general, geoscience research involves highly sophisticated processes of spatial thinking. The cognitive tasks for spatial thinking in the geosciences are partially overlap with the three steps above (Kastens and Ishikawa, 2006)

\section{Geospatial Based Coastal Ecotourism Management}

Coast is defines as the transitional area between the land and the soil types that surrounds all kinds of natural water masses such as sea, lake, or river (Longhorn, 2004). Coastal area is a rich environment of high biological and physical diversity. Its ecosystem is defined by the interaction of terrestrial and marine habitats such as estuaries, coral reefs, seagrass beds, beaches and dune systems. It is learnt from literatures that there are vast potential of social and economic benefits of coast to humanity (Ernsteins, 2010). Agriculture, fisheries and forestry have been among the key economic resources in coastal areas for a long time. However, another important economic contributor to the GDP in terms of foreign currency is tourism. Coastal zone is a complex and difficult area to manage because it consists of marine and terrestrial environment. Overlapping of terrestrial geography and hydrography, temporal processes, competing interest of stakeholders, jurisdiction and legal mandates both locally and international, increase the complexity (Wu et al., 2012). Therefore, issues such as the socio-economic, environmental protection, biodiversity conservation and climate adaptations are pressing issues that requires knowledge to understand and manage. These can be expedited by using integrated coastal reliable spatial information. Once the coastal information system that can store coastal spatial datasets is built, it can be made available to the user community.

Variety of coastal landforms such as dunes, beaches and inlets have been considered as attractive tourist destinations. The beach area of islands, especially, is the most attractive to tourism development with various recreational and ecotourism opportunities, the fact that make their existence as the economic backbone of many barrier island communities. Tourism is a highly fragmented activity as it is located in specific environments and destinations, where there is a variety of environmental, cultural, social and physical attractions. Thus, coastal based tourism and recreation have become one of the significant growing areas of modern tourism (Hall, 2001). However, there is still lack of reliable data on the utilization of a specific shoreline by the people in the process of access planning. The integration of field surveys and geospatial technologies such as geographic information system (GIS) and Global Positioning System (GPS) offer reasonable solutions to develop a geodatabase for more effective shoreline management (Thompson and Dalton, 2010). In addition, with appropriate systems or tools, these technologies can be used to assist the local government in communicating with the public about the beach availability such as map displays and visualizations of projected tide levels with dry beach areas to promote coastal tourism. For example, specific information regarding beach availability may be presented through signs at access points or served by application of web based GIS. In particular, geospatial technologies via Internet and mobile devices such as smart phones can contribute to a spatial decision supporting system (SDSS) for efficient coastal tourism and management, and recreational planning.(Yang, Madden, Kim, and Jordan, 2012).

The origins of the term ecotourism (ecological tourism) is unclear, but was first used by Hetzer (1965), who identified four principles of responsible tourism: minimizing environmental impacts, respecting host cultures, maximizing the benefits to local people and maximizing tourist satisfaction. Since then, many scholars have discussed the definitions of ecotourism as presented in Table 1. Three dimensions represent the main essence of the ecotourism concept i.e. nature based, environmentally educated and sustainably managed. Referring to the fundamental principles, ecotourism should be nature-friendly, ecologically sustainable, environmentally educative, economically beneficial to the local community and offer satisfaction to the tourists (Page and Dowling 2002). The fundamental function of the ecotourism is the protection of the natural and cultural resources as well as income generation, education, local participation and the capacity 
building. Coastal tourism can be considered as an abstract component of biodiversity resources or also known as ecotourism. Ecotourism, or ecotour, is a kind of alternative tourism that is different from the traditional mass tourism. Its purpose is to maintain unique local natural and cultural resources, improve the quality of life of local residents, make tourism resources sustainable, and minimize local environmental impact from tourism. Ecotourism was also used to solve the existing problems of conservation, tourism and local community development. For the ideal and purpose of ecotourism, it is an opportunity for transforming tourism, and is also the new trend for the future development of the tourism industry.

In managing coast, concepts such as coastal atlas, coastal GIS, coastal web, and coastal or marine spatial data infrastructure (SDI) have been used together with Integrated Coastal Zone Management (ICZM), which is a management process itself. An atlas generally is a collection of maps of earth or part of it showing geographic features, locations, socioeconomic and geopolitical information while GIS emphasis on spatial data manipulation and analysis to assist decision making process. In detail, coastal atlas is an online mapping and planning tool that enable data exploration and analysis for coastal and ocean planning tasks (Katsanevakis et al., 2011). ICZM concept evolved to enable coastal zone to be managed using integrated approach with respect to geographic and political boundaries to ensure sustainable management (Wu et al. 2012).

Table 1 Selected Definitions of Ecotourism

\begin{tabular}{lll}
\hline Source & Definition \\
\hline Ceballos-Lascurain (1987) & $\begin{array}{l}\text { Travelling to relatively undisturbed or uncontaminated } \\
\text { natural areas with the specific objective of studying, } \\
\text { admiring and enjoying the scenery and its wild plants and } \\
\text { animals, as well as any existing cultural manifestations (both } \\
\text { past and present) found in these areas }\end{array}$ \\
\hline The Ecotourism Society (1991) & $\begin{array}{l}\text { Responsible travel to natural areas which conserves the } \\
\text { environment and improves the well-being of local people }\end{array}$ \\
\hline $\begin{array}{l}\text { Ecotourism Association of Australia } \\
(1992)\end{array}$ & $\begin{array}{l}\text { Ecologically sustainable tourism that fosters environmental } \\
\text { and cultural understanding, appreciation and conservation }\end{array}$ \\
\hline $\begin{array}{l}\text { National Ecotourism Strategy of Australia } \\
\text { (Allcock et al., 1994) }\end{array}$ & $\begin{array}{l}\text { Ecotourism is nature-based tourism that involves education } \\
\text { and interpretation of the natural environmental and is } \\
\text { managed to be ecologically sustainable } \\
\text { This definition recognizes that 'natural environment' } \\
\text { includes cultural components and that 'ecologically } \\
\text { sustainable' involves am appropriate return to the local } \\
\text { community and long term conservation of the resource }\end{array}$ \\
\hline Tickell (1994) & $\begin{array}{l}\text { Travel to enjoy the world's amazing diversity of natural life } \\
\text { and human culture without causing damage to either }\end{array}$
\end{tabular}

Source: Weaver, 2001

GIS can be used to carry out overlay analysis of the thematic and attribute layers from ecotourism resource indicators, and then presented in the map form of distribution of potential ecotourism resource areas. GIS is a tool that has been widely used in tourism studies because it facilitates in preparing the maps of natural resources (Gul, 2006). Remote sensing and GIS have also been used for the identification of potential ecotourism sites (PES) based on the environmental indicators such as ecological sensitivity, environmental resilience and ecotourism attractions (Arrowsmith and Inbakaran 2002). Remote sensing not only provides the spatial data but also allows the comparison of the temporal variations in the habitat features (Lillesand and Kiefer 2004). The identification of ecotourism indicators for identification of PES and sustainability assessment of ecotourism destination are two examples that can be developed using geospatial technologies. Use of ecotourism indicators will help in identifying the potential ecotourism sites based on the environmental parameters. This can also have its implication at the site level environmental management of ecotourism activity based on ecotourism attractions, ecological fragility and environmental resilience (Kumari et al., 2010). The GIS is suitable to engage the various criteria affecting the development of ecotourism destinations for it could develops new method that can significantly facilitate planning for ecotourism development with respect to ecological capability of ecotourism destinations. 


\section{Conclusion}

Bloom's Taxonomy outlines six taxonomical levels that represent the cognitive stages of thinking. Consideration of these stages can ensure that ICTs are used in Geography teaching material with appropriate meaning and relevance while contributing to learning outcomes. In general, remembering, understanding and applying are considered lower-order thinking skills, but analyzing, evaluating and creating which are more relevant to geospatial technology are considered higher-order thinking skills for university students. In 2009, the revised version of Bloom's Taxonomy incorporated the use of digital tools in the classroom. He provides information on the development of the theory over time, and the inclusion of a digital taxonomy, its impacts on the thinking stages and examples of practice.

GIS can be used to provide resource managers and decision-makers with tools to monitor ecotourism progress towards achieving marine conservation targets. GIS can be applied to integrate information to explore the interactions among human activities and marine resources. Cumulative impact overlays can also be useful in the development of spatial management scenarios to identify hotspot areas of human activity and threat as well as areas of importance for conservation. Additionally, the application of GIS (in terms of information integration, summarization, and visualization) proved beneficial in that it easily allowed for spatially-based ecosystem-level analyses and could be presented in ways that will increase stakeholder understanding of information generated thus support interactive governance.

\section{Reference}

Allcock, A., Jones, B., Lane, S. and J. Grant. (1994). National Ecotourism Strategy. Commonwealth Department of Tourism, Australian Government Publishing Service. Canberra

Arrowsmith, C and R. Inbakaran. (2002). Estimating Environmental Resiliency for the Grampians National Park, Victoria, Australia: a quantitative approach. Tourism Management. 23: 295-309

Catling, S. (2005). The Holy Grail for Geography: Primary School Geography. http://spatialworlds.blogspot.com.au/2012/07/geographies-holy-grail-primary-school.html

Chang Ceballos-Lascurain. (1987). The Future of Ecotourism. Mexico Journal. January. Pp.13-14

Dempsey, C. (2014). What is the Difference between GIS and Geospatial. https://www.gislounge.com/difference-gis-geospatial/ Ecotourism Association of Australia. 1992. Newsletter 1, 2.

Ernsteins, R. (2010). Participation and Integration are Key to Coastal Management. Science for Environment Policy. 19: 1-8

Gul, A.M., K. Orucu, and K. Oznur. (2006). An Approach for Recreation Suitability Analysis to Recreation Planning in Golchuk Nature Park. Journal of Environmental Management 1: 606-625

Hall, M.C. (2001). Trends in Ocean And Coastal Tourism: The End of The Last Frontier?, Ocean \& Coastal Management, 44: 601-618

Hetzer, W. (1965). Environment, Tourism, Culture. Links, July: 1-3

Idrees, M. O. (2015). Challenges in Coastal Spatial data Infrastructure Implementation: A review. South African Journal of Geomatics. Vol. 4: 369-383

Kastens, K. A. and T. Ishikawa. (2006). Spatial Thinking in the Geosciences and Cognitive Sciences: A Cross-Diciplinary Look at the Intersections of the Two Fields. Geological Society of America. Special Paper, 413: 53-76

Katsanevakis, S., V. Stelzenmuller, A. South, T.K. Sorensen, P.J.S. Jones, S. Ker, S. Hofstede, and R. Ter. (2011). Ecosystem-Based Marine Spatial Management: Review of Concepts, Policies, Tools and Critical Issues. Ocean and Coastal Management, 54: 807-820

Kumari, S., M.D. Behera, and H.R. Tewari. (2010). Identification of Potential Ecotourism Sites in West District, Sikkim Using Geospatial Tools. Tropical Ecology 51: 75-85

Longhorn, R. (2004). Integrated Coastal/Marine Spatial Data Infrastructure. www.gisig.it/eco-imagine/full papers/Longhorn.PDF

Page, S. J., and R.K. Dowling. (2002). Ecotourism. England: Prentice Hall

Ross, S. and G. Wall, G. (1999). Ecotourism: Towards Congruence between Theory and Practice. Tourism Management 20: 123-132

The Ecotourism Society. (1991). The Ecotourism Society Newsletter. No. 1. Spring 
Thompson, R., and T. Dalton. (2010). Measuring Public Access to the Shoreline: The BoatBased Offset Survey Method. Coastal Management. 38: 378-398

Tickell, C. (1994). Fareword. In Caler, E. \& Lowman, G. (eds) Ecotourism: A Sustainable Option? John Wiley \& Sons. Brisbane

Wakabayashi, Y. and T. Ishikawa, T. (2011). Spatial Thinking in Geographic Information Science: A Review of Past Studies and Prospects for the Future. Procedia Social and Behavioral Sciences 21: 304 313

Weaver, D. B. (2001). The Encyclopedia of Ecotourism. CABI International

Wu, X. Q., M. Gao, D. Wang, Y. Wang, Q.S. Lu and Z.D. Zhang. (2012). Framework and Practice of Integrated Coastal Zone Management in Shandong Province, China. Ocean \& Coastal Management. 69: 58-67

Yang, B., M. Madden, J. Kim, J. and T.R. Jordan. (2012). Geospatial Analysis of Barrier Island Beach Availability to Tourists. Tourism Management. 33: 840-854

Safiah @Yusmah Muhammad Yusoff

Deputy Dean (Undergraduate), Faculty of Arts and Social Sciences, University Malaya, 50603 Kuala Lumpur, MALAYSIA and Senior Lecturer, Department of Geography, Faculty of Arts and Social Sciences,

University Malaya, 50603 Kuala Lumpur, MALAYSIA 